\title{
Short communication: Two dominant paternal lineages for North American Jersey artificial insemination sires
}

\author{
C. D. Dechow, ${ }^{* 1}$ W. S. Liu, ${ }^{*}$ J. S. Idun, ${ }^{*}$ and B. Maness $†$ \\ *Department of Animal Science, Penn State University, 324 Henning Bldg., University Park 16802 \\ †Jersey Origins LLC, 4056-A Commercial St., Stitzer, WI 53835
}

\begin{abstract}
Jersey cattle are the second most prominent breed in the United States and represent a growing portion of the dairy cow population in the United States. The objectives of our study were to determine the male lineages of Jersey sires with official genetic evaluations and to determine whether there are differences in sire conception rate among lineages. Paternal lineages back to the 1950s were extracted from genetic evaluation files of the Council on Dairy Cattle Breeding (CDCB, Bowie, MD) for all sires with an official United States genetic evaluation and that were enrolled with the National Association of Animal Breeders (Madison, WI). Further tracing of male lineages was performed by accessing the pedigree database of Jersey Origins LLC (Stitzer, WI). Only paternal lineages were considered because we were interested in transmission of the Y chromosome. Sire conception rate evaluations were also retrieved from CDCB for 1,116 bulls. Nearly all North American bulls born in the decade beginning 2010 could be traced to Secret Signal Observer or Advancer Sleeping Jester, who together account for $98.9 \%$ of paternal lineages. Both bulls plus the 3 additional bulls that account for the remaining 1.1\% of current descendants can be traced to a single bull (Champion Flying Fox) born on the island of Jersey in 1898. When considering sires imported into the United States, the majority $(71 \%)$ trace their paternal lineage to Secret Signal Observer or Advancer Sleeping Jester, and $97 \%$ can be traced to Champion Flying Fox. Sire conception rates were higher by 0.30 percentage points in the Secret Signal Observer line than in the Advancer Sleeping Jester line, which was significant. The small number of paternal lineages for recently born artificial insemination Jersey sires indicates that there is limited genetic diversity for much of the $\mathrm{Y}$ chromosome, suggesting that autosomal variation may be a more impor-
\end{abstract}

Received August 16, 2017

Accepted November 7, 2017.

${ }^{1}$ Corresponding author: cdd1@psu.edu tant source for differences in male fertility than the $\mathrm{Y}$ chromosome.

Key words: Jersey, Y chromosome, paternal

\section{Short Communication}

Higher male fertility increases the value of semen (Pecsok et al., 1994) because high reproductive efficiency is essential to profitable dairy production; the value of establishing a new pregnancy was estimated to be $\$ 278$ (De Vries, 2006) when comparing the future cash flows of a pregnant cow to those of a nonpregnant cow. Sire conception rate (SCR) was established as a national phenotypic predictor of male fertility in 2008 (Kuhn and Hutchison, 2008) and replaced estimated relative conception rate, which had been available beginning in 1986 (Clay and McDaniel, 2001; Kuhn and Hutchison, 2008).

Although substantial phenotypic differences exist among sires in conception rate, the genetic component is relatively small and heritability estimates are low (Kuhn and Hutchison, 2008). Nevertheless, molecular pathways that influence male fertility have been identified ( $\mathrm{Li}$ et al., 2012; Han and Penagaricano, 2016). Genetic variation on the $\mathrm{Y}$ chromosome ( $\mathbf{Y}$-chr) has also been shown to influence male fertility in cattle (Yue et al., 2013) and male health and fertility in humans (Bellott et al., 2014). In Holsteins, the amount of genetic diversity on much of Y-chr is expected to be limited because nearly all Holstein sires trace through their male lineage to only 2 sires from the 1960s (Yue et al., 2015). However, some variation is expected because the pseudoautosomal region of the $\mathrm{Y}$-chr $(\sim 5 \%)$ recombines with the $\mathrm{X}$ chromosome during meiosis. There are also multiple copy gene families in the male-specific region that vary among Holstein bulls and that can change rapidly (Chang et al., 2013; Yue et al., 2013).

Jersey cattle are the second most prominent breed in the United States and represent a growing portion of the population, with the proportion of Jersey semen sold domestically by National Association of Animal Breeders (NAAB; Madison, WI) members increasing 
from $6 \%$ in 2000 to $13 \%$ in 2016 (NAAB, 2017). Paternal lineages for Jersey cattle have not been reported on as they have for Holstein. The objectives of our study were to determine the male lineages of Jersey sires with official US genetic evaluations and to determine if differences exist in SCR among Jersey lineages. We focus on male fertility because the Y-chr would not influence cow or heifer conception rate.

Data were extracted from the April 2017 genetic evaluation of the Council on Dairy Cattle Breeding (CDCB, 2017a). The data were used to trace the paternal lineage to the last ancestor born in the 1950 s for all AI sires; we considered lineages from the AI era to be modern era Y-chr lineages. Further tracing of male lineages to Isle of Jersey breeding records was performed by accessing the pedigree database of Jersey Origins LLC (Switzer, WI) to identify island founders. Lineages were initially traced for North American-born sires and subsequently for foreign-born sires with semen imported to the United States and with an official genetic evaluation.

We retrieved August SCR evaluations from the CDCB (CDCB, 2017b) every year from 2008 to 2017. The SCR with the highest reliability for bulls from Jester and Observer lineages was retained. Reliability was required to be at least $50 \%$ to be included in the analysis, resulting in 1,116 sires with SCR records. The association of paternal lineage with SCR was evaluated using the MIXED procedure of SAS (version 9.4, SAS Institute Inc., Cary, NC). Statistically significant $(P<$ 0.05 ) fixed model effects included paternal lineage, age of the sire at his SCR evaluation, and bull stud. The interaction of bull stud and year of SCR evaluation was treated as a random effect and improved model fit (lower Akaike information criterion corrected for finite sample size, AICC); year of SCR evaluation was not a significant fixed effect when this interaction was included but was included to maintain a hierarchical model. The reliability of the SCR evaluation was used as a weighting factor. Least squares means were generated for paternal lineage.

The number of Jersey sires born per decade with an official US genetic evaluation is depicted in Figure 1, along with the number of paternal lineages present by decade. The number of North American-born Jersey sires per decade was 431 in the 1970s and 1,778 (to date) in the decade beginning in 2010. The number of total sires born in the 2010s was 1,929 after including those not born in North America. The number of modern era Y-chr lineages that can be traced in the CDCB system declined to 5 for North American-born bulls in the 2010s compared with 44 in the 1970s.

Some decline in the number of lineages over time is expected, because each generation is a subset of the parent generation. More generations can also be traced for later decades, which could inflate the perception of the number of lineages maintained in earlier decades. To test this, we compared the number of lineages over 2 generations for each decade. Of sires with sufficient pedigree depth available, there were 3.4 descendants per lineage in the 1960s, 9.1 in the $1970 \mathrm{~s}$, and $>15$ for the remaining decades. This suggests that paternal

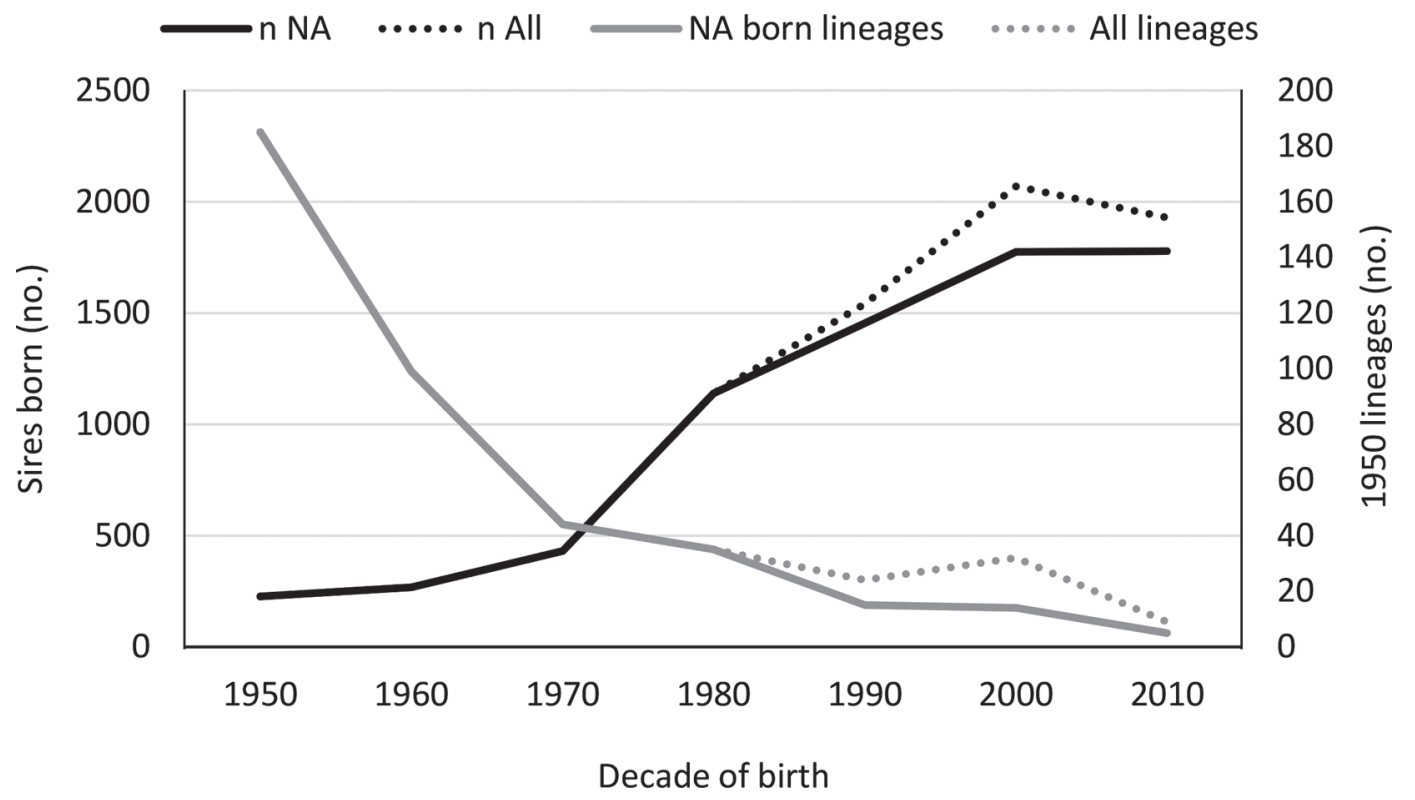

Figure 1. The number of North American born (n NA) and all (n All) AI sires with an official US genetic evaluations, and the number of modern era male lineages (NA born and All lineages) represented by those sires. 


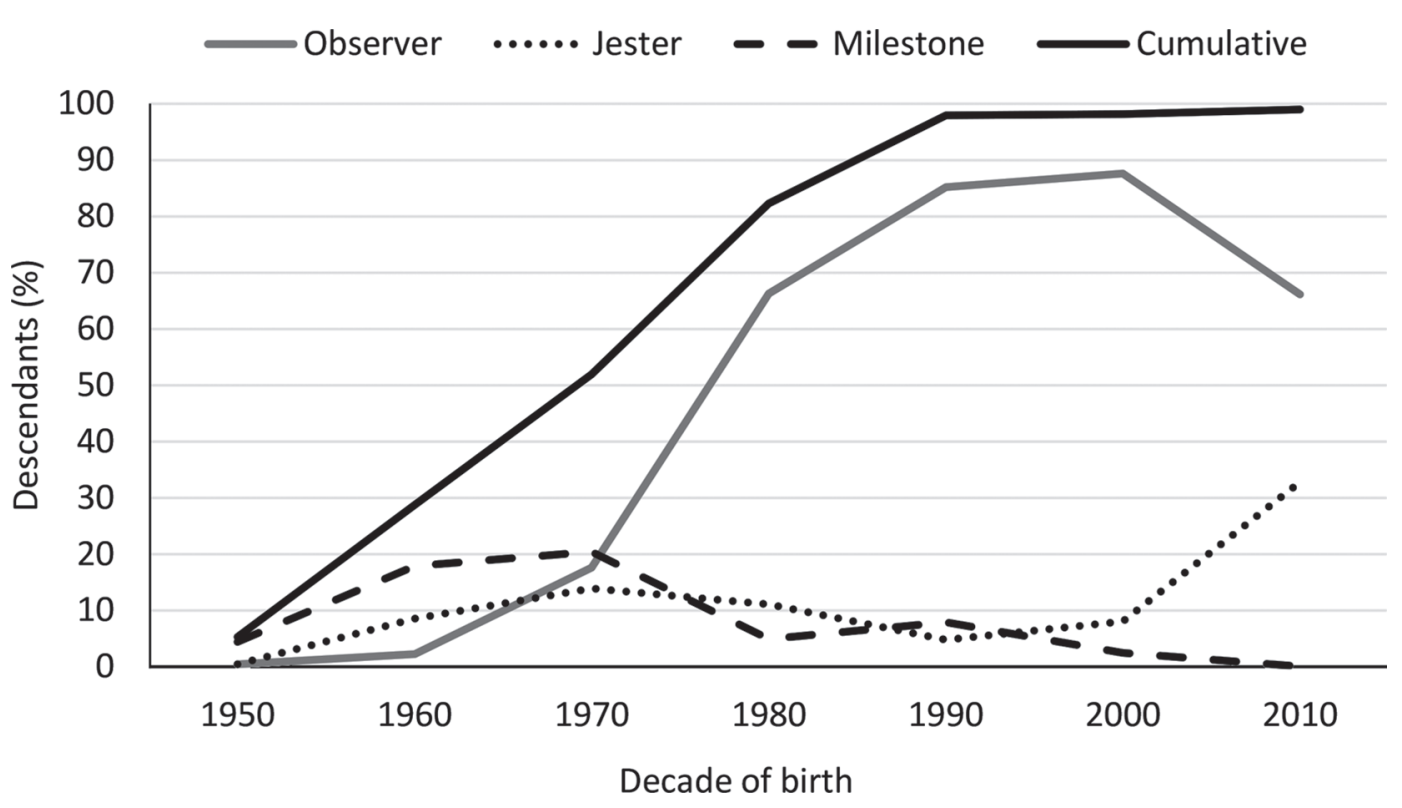

Figure 2. The individual and cumulative percentage of North American born male lineage descendants from 3 modern era sires (Observer, Jester, and Milestone) by decade of descendant's birth.

lineages were lost more rapidly as the adoption of AI became widespread.

The name, identification number, birth year, and number of descendants born in the 2010s for the 5 modern North American Y-chr lineages is reported in Table 1. All 5 lineages trace their paternal ancestry to a single Isle of Jersey bull named Champion Flying Fox, who was born in 1898 . The 4 sires born in the 1950s trace their lineages through his son Agatha's Flying Fox; ISDK FYN Tved was traced through his son Bobby's Shy Fox. Tved's semen was imported into the United States from Denmark, and his paternal lineage was traced through New Zealand and to the Isle of Jersey.

Two dominant modern era Y-chr lineages account for 98.9\% of all North American sires born in the 2010s, with Secret Signal Observer responsible for $66.1 \%$ and Advancer Sleeping Jester for $32.8 \%$. The relative contributions of those 2 bulls plus Marlu Milestone are shown in Figure 2. Milestone had more male descen- dants than the others through the 1970s but has only a single descendant born in the 2010s thus far. Despite being responsible for almost all current paternal lineages descendants, Observer $(5.7 \%$ expected future daughter inbreeding) and Jester (1.7\% expected future daughter inbreeding) are relatively unrelated to the female Jersey population (CDCB, 2017a). Milestone had an expected future daughter inbreeding of $3.4 \%$. This indicates that, although Observer and Jester are responsible for almost all male lineages, many other bulls from the modern AI era have contributed genetic material through female lineages.

Observer lineages can be traced through his sons S.S. Quicksilver of Fallneva (700 descendants from the 2010s) and Observer Chocolate Soldier (476 descendants from the 2010s), who were born in 1960 and 1962, respectively. The recent increase in the lineage of Jester can be attributed to his descendant ISDK Q Impuls (545 descendants in the 2010s), who was born in 1998, and Impuls' 2004 son Tollenaars Impuls Legal

Table 1. The 5 modern North American Y-chromosome lineages

\begin{tabular}{lllrr}
\hline Name & Short name & Identification & Birth year $^{\mathrm{n} \mathrm{Desc}^{1}}$ & $\mathrm{n} \mathrm{Gen}^{2}$ \\
\hline Secret Signal Observer & Observer & JEUSA000000553236 & 1953 & 1,176 \\
Advancer Sleeping Jester & Jester $^{3}$ & JEUSA000000534585 & 1951 & 11 \\
ISDK FYN Tved & Tved $^{3}$ & JEUSA000000645282 & 1974 & 11 \\
L.C. Standard Master & Master $_{\text {Marlu Milestone }}$ & JEUSA000000574191 & 1956 & 16 \\
\hline
\end{tabular}

${ }^{1}$ The number of North American-born AI male lineage descendants with an official US genetic evaluation in the decade beginning in 2010.

${ }^{2}$ The number of generations to common Isle of Jersey founder Champion Flying Fox, who was born in 1898.

${ }^{3}$ Bulls without an official US short name. 
233-ET (428 descendants in the 2010s). The increase of the Jester lineage is likely due to favorable genetic merit of Impuls and his descendants for solids production. Combined PTA for fat and protein yields were higher for the Observer lineage by $2 \mathrm{~kg}$ (2000s) to 39 $\mathrm{kg}$ (1960s), but Jester descendants exceeded Observer descendants by $5 \mathrm{~kg}$ in the 2010s.

The 2010s descendants of L.C. Standard Master and Milestone are controlled by regional NAAB members that have relatively few bulls and appear to be niche market sires. Therefore, one or both of the modern lineages could be lost in the near future. Nevertheless, the current presence of the lineages demonstrates the important role that smaller AI units and individual breeders with different selection goals contribute toward enhancing breed genetic diversity.

Of those bulls not born in North America in the 2010s but with an official evaluation (shown in Supplemental Table S1; https://doi.org/10.3168/jds.2017-13694), $88 \%$ can be traced to Observer, Jester, or Tved. Fourteen of the remaining 18 bulls can be traced to Maori Bestman, whose paternal lineage can be traced through New Zealand to the Isle of Jersey and Champion Flying Fox in 15 generations. Of the remaining 4 sires in Supplemental Table S1, 2 were traced to a KiwiCross sire, 1 was traced to a Holstein sire, and 1 was traced to an Australian bull named Lumeah Expectation, who was born in 1949 and whose paternal lineage we were unable to trace further.

Least squares means of SCR for Observer and Jester were +0.18 and -0.12 , respectively. Observer descendants had significantly higher $(P<0.05)$ SCR than Jester descendants - by 0.30 percentage points. Given the recent increase of the Jester lineage, this relatively small difference in SCR is not enough to offset favorable genetic merit for other traits.

In conclusion, there are 2 primary modern $\mathrm{Y}$-chr lineages for recently born AI Jersey sires, both of which trace paternally to a single Isle of Jersey founder. This suggests that there is limited genetic diversity for much of the Y chromosome, but there is evidence of a small sire fertility difference between those 2 lineages.

\section{ACKNOWLEDGMENTS}

Funding from USDA-Agricultural Research Service award 58-5402-4-015 is greatly appreciated; J. S. Idun was supported by an undergraduate research grant from the College of Agricultural Sciences (Penn State University, University Park). This study was possible thanks to the availability of genetic evaluations from the Council on Dairy Cattle Breeding (Bowie, MD) and ancestor information that was originally assembled by the American Jersey Cattle Association (Reynoldsburg, $\mathrm{OH})$.

\section{REFERENCES}

Bellott, D. W., J. F. Hughes, H. Skaletsky, L. G. Brown, T. Pyntikova, T. J. Cho, N. Koutseva, S. Zaghlul, T. Graves, S. Rock, C. Kremitzki, R. S. Fulton, S. Dugan, Y. Ding, D. Morton, Z. Khan, L. Lewis, C. Buhay, Q. Wang, J. Watt, M. Holder, S. Lee, L. Nazareth, J. Alfoldi, S. Rozen, D. M. Muzny, W. C. Warren, R. A. Gibbs, R. K. Wilson, and D. C. Page. 2014. Mammalian Y chromosomes retain widely expressed dosage-sensitive regulators. Nature 508:494-499.

CDCB. 2017a. Genetic evaluations available from CDCB. Accessed Jul. 9, 2017. https://www.uscdcb.com/eval.htm.

CDCB. 2017b. SCR evaluations. Accessed Jul. 9, 2017. https://www .uscdcb.com/eval/summary/scr_menu.cfm.

Chang, T. C., Y. Yang, E. F. Retzel, and W. S. Liu. 2013. Malespecific region of the bovine $\mathrm{Y}$ chromosome is gene rich with a high transcriptomic activity in testis development. Proc. Natl. Acad. Sci. USA 110:12373-12378.

Clay, J. S., and B. T. McDaniel. 2001. Computing mating bull fertility from DHI nonreturn data. J. Dairy Sci. 84:1238-1245.

De Vries, A. 2006. Economic value of pregnancy in dairy cattle. J. Dairy Sci. 89:3876-3885.

Han, Y., and F. Penagaricano. 2016. Unravelling the genomic architecture of bull fertility in Holstein cattle. BMC Genet. 17:143.

Kuhn, M. T., and J. L. Hutchison. 2008. Prediction of dairy bull fertility from field data: Use of multiple services and identification and utilization of factors affecting bull fertility. J. Dairy Sci. 91:2481-2492.

Li, G., F. Penagaricano, K. A. Weigel, Y. Zhang, G. Rosa, and H. Khatib. 2012. Comparative genomics between fly, mouse, and cattle identifies genes associated with sire conception rate. J. Dairy Sci. 95:6122-6129.

NAAB. 2017. Annual reports of semen sales and custom freezing. Accessed Jul. 9, 2017. http://www.naab-css.org/sales/table_list .html.

Pecsok, S. R., M. L. McGilliard, and R. L. Nebel. 1994. Conception rates. 2. Economic value of unit differences in percentages of sire conception rates. J. Dairy Sci. 77:3016-3021.

Yue, X. P., T. C. Chang, J. M. DeJarnette, C. E. Marshall, C. Z. Lei, and W. S. Liu. 2013. Copy number variation of PRAMEY across breeds and its association with male fertility in Holstein sires. J. Dairy Sci. 96:8024-8034.

Yue, X. P., C. Dechow, and W. S. Liu. 2015. A limited number of Y chromosome lineages is present in North American Holsteins. J. Dairy Sci. 98:2738-2745. 